\title{
Distance Effects in Consumption: Measuring Distance Value with Application to Casino Siting
}

\author{
Earl L. Grinols*
}

\begin{abstract}
Inferring the consumer benefits from reduced distance to the product or service provider plays a central role in the cost-benefit analysis of siting decisions, where the relevant issue is reducing the consumer's distance to the nearest supply point rather than reducing prices or the terms of supply. If visit enjoyment declines with distance, increases with expenditure per visit, and expenditure per visit and number of visits per period are choice variables, then a consumer-surplus-like measure serves as an upper bound on distance benefits. The theory is applied to a CES utility function modified to incorporate distance and benchmarked to casino data.
\end{abstract}

\section{INTRODUCTION}

Many public policy decisions involve site selection for commercial outlets, such as amusement parks, ski resorts, casinos, or other service providers. The primary benefit to consumers of a particular site is closer proximity to the location where the good or service is offered. Being able to visit Disney World by driving five miles to the gate is better than visiting Disney World by driving 500 miles. Once at the service location, the prices and terms of purchase are the same when the service is offered nearby as they are if the service is offered at a site farther away. A consumer surplus approach, therefore, which depends on price differences, does not apply to computing the benefits to consumers of a nearby siting choice. Researchers have nevertheless searched for measures similar to consumer surplus in order to construct values for amenities or attributes of consumption (like distance from site or lowered water pollution at a beach) by observing consumption of related goods. How much one is willing to assume about the nature of the amenity, the particular features of demand for the observable, and how the two relate determine the parameters of the problem.

Knowing the direct consumer benefits of nearby siting is a key component of the benefit side of cost-benefit analysis for a siting selection. Observations on how the number of visits per year and the amount spent per visit vary with distance are often available. A visitor to Disney World or a casino who has to travel a great distance generally responds by visiting less frequently, but spending more per visit when a visit is taken. The total annual expenditure per capita generally falls with distance. Can information on the frequency of visits and the amount spent per visit be used to infer the benefits to consumers of placing a Disney World or a casino close to a metropolitan area compared to a site farther away? How would distance benefits be incorporated into a general cost-benefit calculation

*Professor, Department of Economics, University of Illinois, Champaign, Illinois. I would like to thank the anonymous referees for their comments. 
so that there is no economy-wide double counting and all numbers are consistently computed?

The problem of benefit valuation in these and related problems is not trivial and has often been mishandled. Bockstael and McConnell (1993), for example, observe that "...empirical studies frequently reveal considerable confusion, especially when welfare correspondences well established for price changes are analogously attributed to quality changes. Assumptions about the equivalence of price and quality changes have led to unfounded conclusions about the relative sizes of consumer surplus and compensating and equivalent variation" (p. 1244).

The complex relationship between distance and demand is one that in principle can include many considerations. Often these considerations differ by individual, even for the same circumstances. For example, where one consumer might enjoy the act of driving over interesting terrain to reach a casino site, another might view it as an unpleasant chore. In some cases, it may not be possible to capture the most important consumer demand considerations except in an explicitly intertemporal framework. However, the economics profession has tended to resist taking a universal intertemporal utility approach, favoring whenever possible the atemporal utility approach that has served it so well, even though all consumption is, at its core, intertemporal.

Among the approaches that have been investigated for siting problems, the foremost-the travel-cost approach-uses the link between greater distance and higher cost of obtaining a service as a way to adapt consumer surplus ideas to measure the benefits of nearer provision. The idea is that distance between a recreation site and an individual's origin (typically his home) produces a pseudo price for visits that declines with closer siting. Integrating under the appropriate demand curve between constructed prices produces a measure of consumer benefit from lower prices/closer provision. Because time costs are often a significant part of the costs of travel, travel-cost approaches are often closely allied to the literature on how time enters into household production, consumption, and budget constraints associated with Becker $(1965,1996)$ and others. ${ }^{1}$ Placing a value on the household's time in the travel-cost approach is a particularly tricky issue, with ad hoc rules scaling wages by factors of one-fourth to one-half the most common approach. ${ }^{2}$ The multi-attribute aspect of recreation trips (consumption of multiple goods often characterizes recreation choices) has led a number of articles in the travel-cost literature to consider random utility models when the problem involves selecting between alternate sites for the same or similar service. While under certain circumstances a travel-cost approach might be precisely correct, it usually requires particular assumptions that do not apply equally well to all problems. ${ }^{3}$ In Bockstael and McConnell (1993), the problem of interest is that some parameter (a public good, such as water quality at a beach) enters utility directly and inferences about the value of changing the level of the parameter are sought by observations on household purchases of associated private goods (use of the ${ }^{1}$ Smith (1997) provides an excellent survey of time in the context of the valuation of environmental resources.

${ }^{2}$ See, for example, Larson (1993) and McConnell and Strand (1981) for a discussion of theoretical underpinnings.

${ }^{3}$ Entrance to the extensive travel-cost and time-cost literature can be found from the references cited. 
beach) at constant market prices. This problem has features in common with the distance question addressed here, but differs from the present problem because prices for the private good are parametrically constant. With respect to gambling, consumers choose both the number of visits (quantity) and the amount spent per visit ("price"). Further, greater enjoyment, ceteris paribus, results from higher expenditures per visit, which would not appear to apply in general to other problems.

This paper therefore investigates the question of using information about distance, frequency of visits, and amount spent per visit to infer consumer benefits from closer availability as it applies to gambling (and similar services), where the amount spent per visit is a choice of the household. ${ }^{4}$ Section II shows how the relevant components should be scaled in general equilibrium to provide a theoretically grounded commensurable measure for costs and benefits. Section III then looks at the most important component of benefits-the direct consumer benefits of smaller $\mathrm{d}$, the distance to the nearest service location. It modifies the consumer's choice problem to take account of distance, and applies the relevant first order conditions to consumer optimization to show how observations of d, visit frequency, $V$, and amount spent per visit, g, relate to consumer welfare. The analysis leads to construction of an intuitive upper bound on distance benefits based on observations of $\mathrm{g}$ and $\mathrm{V}$ that can precisely equal true benefits in some cases. Section IV then applies data from the casino industry to benchmark two alternative functional forms. It uses the benchmarked forms to calculate the true value to consumers of having casinos located within a few miles compared to the pre-1990 alternative of having to travel to Nevada or Atlantic City. The bound performs appropriately, but in this example does not give a close approximation to the true distance benefits generated by the benchmarked forms.

\section{INCLUDING DISTANCE BENEFITS IN COST-BENEFIT}

The expenditure function measures utility by the amount of income needed at given prices to achieve a desired level of utility. Let $e_{i}\left(p, d, u_{i}\right)$ be consumer $i^{\prime} s$ expenditure function where $\mathrm{p}$ is a vector of market prices, ${ }^{5} \mathrm{~d}$ is the distance to the nearest provider, and $\mathrm{u}$ is the utility level. From the consumer's perspective, both $\mathrm{p}$ and $\mathrm{d}$ are exogenously fixed parameters of the consumer's choice problem. Let superscript 0 denote the initial situation, in which the provider is farther away, and superscript 1 denote the situation in which the provider is closer. Thus, $\mathrm{d}^{0}>\mathrm{d}^{\mathrm{i}}$.

We use standard general equilibrium notation and identities that relate expenditure to income and its components. Vector $y_{j}$ is the production decision of firm j. Positive elements represent outputs and negative elements represent use of inputs. The vector of consumption and labor supply decisions of consumer $i$ is denoted by $x_{i}$. A positive component of $x_{i}$ represents consumption of the good in question, while a negative component, say, labor, represents a good ${ }^{4}$ Components of the social costs and economic effects of casinos have generally been more readily measured than their benefits (e.g., Lesieur 1996, Grinols 1994, 1995, 1996; Grinols and Omorov 1997). There is a need for developing applicable benefit measures.

${ }_{5}^{5}$ The vector $p$ does not include the amount spent per visit to casinos because that is a choice variable for the consumer in the problem we consider. The fact that the consumer decides how many visits to make and how much to spend per visit based on how far away the facility is distinguishes this problem. 
supplied. The vector of nonproduced endowments of the economy is denoted by $\omega$, and $\sum_{j} y_{j}+\omega$ is total production for the economy.

Next, let $\mathrm{z}$ be the vector of economy net imports where a positive element indicates that the corresponding good is imported. Negative elements represent exports. A zero component of $z$ stands for a nontraded good. Taxes imply that different firms and households may face different prices. Using income and expenditure identities we have

$$
\begin{aligned}
& \sum_{i}\left(e_{i}\left(p_{i}^{1}, d^{1}, u_{i}^{1}\right)-e_{i}\left(p_{i}^{0}, d^{0}, u_{i}^{0}\right)\right) \\
& =\sum_{i}\left(p_{i}^{1} \cdot x_{i}^{1}-p_{i}^{0} \cdot x_{i}^{0}\right) \\
& =\left(\sum_{j} p_{j}^{1} \cdot y_{j}^{1}-\sum_{j} p_{j}^{0} \cdot y_{j}^{0}\right)+\left(p^{1}-p^{0}\right) \cdot \omega+p^{1} \cdot z^{1}-p^{0} \cdot z^{0} \\
& +\left(\sum_{i}\left(p_{i}^{1}-p^{1}\right) \cdot x_{i}^{1}-\sum_{i}\left(p_{i}^{0}-p^{0}\right) \cdot x_{i}^{0}\right) \\
& +\left(\sum_{j}\left(p^{1}-p_{j}^{1}\right) \cdot y_{j}^{1}-\sum_{j}\left(p^{0}-p_{j}^{0}\right) \cdot y_{j}^{0}\right) \\
& =\Delta \text { Profits }+\left(p^{1}-p^{0}\right) \cdot \omega+\Delta \text { Taxes, }
\end{aligned}
$$

where firm profits are measured as after-tax profits.

If more casinos are introduced when previously they existed only in a few locations, the only change to consumers is that the distance to the nearest casino is reduced. We use the expenditure function to measure the benefit of casino introduction as follows:

$$
\begin{aligned}
\text { Benefit } \equiv & \sum_{i}\left[e_{i}\left(p_{i}^{1}, d^{1}, u_{i}^{1}\right)-e_{i}\left(p_{i}^{1}, d^{1}, u_{i}^{0}\right)\right] \\
= & \sum_{i}\left[e_{i}\left(p_{i}^{0}, d^{0}, u_{i}^{0}\right)-e_{i}\left(p_{i}^{0}, d^{1}, u_{i}^{0}\right)\right]+\sum_{i}\left[e_{i}\left(p_{i}^{1}, d^{1}, u_{i}^{1}\right)-e_{i}\left(p_{i}^{0}, d^{0}, u_{i}^{0}\right)\right] \\
& +\sum_{i}\left[e_{i}\left(p_{i}^{0}, d^{1}, u_{i}^{0}\right)-e_{i}\left(p_{i}^{1}, d^{1}, u_{i}^{0}\right)\right] \\
= & \sum_{i} \int_{d^{0}}^{d^{1}} \frac{\partial e_{i}}{\partial d} d d+\left[\Delta \text { Profits }+\left(p^{1}-p^{0}\right) \cdot \omega+\Delta \text { Taxes }\right] \\
& +\Delta \text { Consumer Surplus } \\
= & \sum_{i} \int_{d^{0}}^{d^{1}} \frac{\partial e_{i}}{\partial d} d d+\Delta \text { Profits }+\Delta \text { Taxes. }
\end{aligned}
$$

The first line is an identity by addition and subtraction of terms. The second follows from rewriting the discrete difference, $e\left(\mathrm{p}^{0}, \mathrm{~d}^{0}, \mathrm{u}^{0}\right)-\mathrm{e}\left(\mathrm{p}^{0}, \mathrm{~d}^{1}, \mathrm{u}^{0}\right)$, in integral form, substituting from (1), and the definition of consumer surplus. The last line follows from the assumption that the entertainment provider is small 
relative to the economy so that its siting does not change economy-wide prices, $\mathrm{p}^{0}=\mathrm{p}^{1}$. Consumer surplus and the change in value of nonproduced endowment income drop out leaving only the direct benefit to consumers of the distance reduction, change in profits, and change in taxes collected.

Notice that the changes in profits and taxes involve variations for the entire economy. The increased profit from a new casino, for example, must be balanced by the reduction in profits elsewhere. According to rule (2), only the net increase in profits counts as a social benefit. A similar remark applies to taxes. Since the degree to which profits and taxes of casinos exceed the profits and taxes of alternate uses of resources is probably not large, the primary benefit of casino expansion is likely to consist of distance benefits to consumers. We therefore turn our attention next to a discussion of the benefit term, $\frac{\partial \mathrm{e}}{\partial \mathrm{d}^{\prime}}$, which the general formula identified.

\section{DISTANCE AND DEMAND}

The consumer facing the prospect of a long trip to enjoy skiing generally plans to ski several days rather than the afternoon he might have planned were the ski resort just a few minutes down the road. He responds to the increased distance by reducing the number of trips he takes per season, but increasing the amount spent per trip. We would expect the total expenditure (visits times expenditure per visit) on skiing to be higher for the individual who lives next door to the slopes (he is more likely to buy a season lift ticket and ski frequently in numerous smaller trips, for example) than for the individual who must travel half a continent. Such behavior applies across a wide range of leisure activities and presumably has to do with the fixed costs and economies of scale in the consumer's production of enjoyment. If the consumer has to travel far to obtain the recreation, he will make sure that the trip is a big enough one to make the effort worthwhile.

In this section we consider a class of utility functions consistent with this behavior and use them to generate the associated expenditure function. We examine whether it is possible to gather information about the value of closer siting from observations of distance, number of trips, and purchases of other goods. ${ }^{6}$ Here we pay special attention to the additional information derived from the choice that the consumer makes of how much to spend per visit. Since we use casino data to benchmark a function of the type considered, we interpret $\mathrm{V}$ as the number of visits per year, $g$ as the typical amount gambled (lost) at the casino per visit, and $\mathrm{d}$ as the distance to the nearest casino in placing bounds on $\frac{\partial \mathrm{e}}{\partial \mathrm{d}}$ in the general case and computing exact distance benefits in a special case.

\section{A. Utility and Distance}

Assume that there are two goods, a composite good, $x$, and casino visits, $\mathrm{V}$. All else held constant, the consumer prefers a casino visit that is associated with traveling a small distance rather than a larger distance. In addition, not all ${ }^{6}$ See Bockstael and McConnell (1993) for a discussion of why the question can be answered, but not always successfully except in special cases, in the related question of valuing public goods treated as parameters of the consumer's choice problem. 
gambling visits give the same utility. We assume that a casino visit during which more gambling takes place is preferred, ceteris paribus, to one with less gambling. To capture the notion that the enjoyment attached to a gambling visit varies with amount gambled and distance traveled, let I represent "visit intensity" - the enjoyment factor associated with a gambling visit. We have $I=I(g, d)$, where $\frac{\partial \mathrm{e}}{\partial \mathrm{g}}>0$ and $\frac{\partial \mathrm{e}}{\partial \mathrm{d}}<0$ by hypothesis. If utility depends both on the number of visits and the intensity or enjoyment level attached to each visit, given by $I(g, d)$, the most general class of utility functions incorporating $\mathrm{V}, \mathrm{x}$, and $\mathrm{I}$ would be

$$
\mathrm{u}=\mathrm{u}(\mathrm{x}, \mathrm{V}, \mathrm{I}(\mathrm{g}, \mathrm{d})) \text {, }
$$

where utility rises in each of the arguments $\mathrm{x}, \mathrm{V}$, and $\mathrm{I}$.

Before proceeding, we review the particular issues that distinguish gambling in deciding the form of utility. In purchasing a conventional private good, only the quantity consumed enters utility. Price does not enter utility and price is not a consumer choice. In gambling, the visit plays the role of quantity, and the amount gambled per visit plays the role of "price," or cost, of a visit. Both the number of visits and the amount gambled per visit matter to enjoyment. Both variables, not just the quantity variable, are consumer choices. While we could write utility as a nonspecific function of $(x, V, g, d)$, if we take visits as the primary agent of utility creation and the visit "intensity" as an enjoyment factor that matters to how a visit is viewed by the consumer, we are forced to make assumptions as in (3) with particular psychological implications. These assumptions seem reasonable and, in any event, are the ones that we wish to investigate.

We now construct from $u$ the expenditure function referred to in the previous section and examine it for useable connections between $\mathrm{g}, \mathrm{V}$, and $\mathrm{d}$.

\section{B. Expenditure and Demand}

The expenditure function results from minimizing the expenditure, $\mathrm{px}+\mathrm{gV}$, needed to achieve a given level of utility where the consumer takes distance, $d$, and the price, $p$, of good $x$ as given, but is free to choose how much $x$ to consume, how many visits, $\mathrm{V}$, to make and how much to spend, $\mathrm{g}$, per visit.

The Lagrangian associated with the minimization is

$$
\mathrm{L}=\mathrm{px}+\mathrm{gV}+\lambda[\mathrm{u}-\mathrm{u}(\mathrm{x}, \mathrm{V}, \mathrm{I}(\mathrm{g}, \mathrm{d}))] \text {, }
$$

where $\lambda$ is the Lagrangian multiplier. $\lambda$ is interpreted as the marginal cost of an additional unit of utility. The associated first order conditions to the minimization are

$$
\begin{array}{ll}
\frac{\partial \mathrm{L}}{\partial \mathrm{x}}: & \mathrm{p}=\lambda \mathrm{u}_{\mathrm{x}} \\
\frac{\partial \mathrm{L}}{\partial \mathrm{V}}: & \mathrm{g}=\lambda \mathrm{u}_{\mathrm{V}} \\
\frac{\partial \mathrm{L}}{\partial \mathrm{g}}: & \mathrm{V}=\lambda \mathrm{u}_{\mathrm{I}} \mathrm{I}_{\mathrm{g}},
\end{array}
$$


where subscript denotes partial differentiation.

Applying the envelope theorem to expenditure,

$$
\frac{\partial \mathrm{e}}{\partial \mathrm{d}}=\frac{\partial \mathrm{L}}{\partial \mathrm{d}}=-\lambda \mathrm{u}_{\mathrm{I}} \mathrm{I}_{\mathrm{d}} \text {. }
$$

Since $u_{I}$ and $I_{d}$ are positive and negative, respectively, $\frac{\partial e}{\partial d}>0$. Thus, expenditure rises to keep utility from falling when distance to the nearest casino increases. If $g(d)$ is the optimizing choice of $g$ as a function of $d$, intensity changes with $d$ according to $I(g(d), d)$, where

$$
\frac{\mathrm{dI}}{\mathrm{dd}}=\mathrm{I}_{\mathrm{g}} \frac{\partial \mathrm{g}}{\partial \mathrm{d}}+\mathrm{I}_{\mathrm{d}} \text {. }
$$

Substituting (7) into the formula for $\frac{\partial \mathrm{e}}{\partial \mathrm{d}^{\prime}}$ above, and using the first order conditions gives

$$
\begin{aligned}
\frac{\partial \mathrm{e}}{\partial \mathrm{d}} \mathrm{dd} & =-\lambda \mathrm{u}_{\mathrm{I}} \mathrm{I}_{\mathrm{d}} \mathrm{dd} \\
& =-\lambda \mathrm{u}_{\mathrm{I}}\left(\frac{\mathrm{dI}}{\mathrm{dd}}-\mathrm{I}_{\mathrm{g}} \frac{\partial \mathrm{g}}{\partial \mathrm{d}}\right) \mathrm{dd} \\
& =\lambda \mathrm{u}_{\mathrm{I}} \mathrm{I}_{\mathrm{g}} \frac{\mathrm{dg}}{\mathrm{dd}} \mathrm{dd}-\lambda \mathrm{u}_{\mathrm{I}} \frac{\mathrm{dI}}{\mathrm{dd}} \mathrm{dd} \\
& =\mathrm{V} \frac{\mathrm{dg}}{\mathrm{dd}} \mathrm{dd}-\lambda \mathrm{u}_{\mathrm{I}} \frac{\mathrm{dI}}{\mathrm{dd}} \mathrm{dd} \\
& =\mathrm{Vdg}-\lambda \mathrm{u}_{\mathrm{I}} \mathrm{dI} \\
& \leq \mathrm{Vdg} .
\end{aligned}
$$

The last inequality follows from the fact that $\lambda$ and $u_{I}$ are positive and the assumption that $\frac{\mathrm{dl}}{\mathrm{dd}}$ is nonnegative. ${ }^{7}$ Thus, expression (8) indicates that observations of expenditure and frequency of visits can provide information-in this case, an upper bound-on the value to the consumer of having the service location nearer. If visits are enjoyed equally, $\frac{\mathrm{dl}}{\mathrm{dd}}=0$, the measure given by Vdg is exact. This latter condition means that if a consumer visits a casino from a greater distance, he increases his spending to keep his enjoyment of the visit from falling relative to the enjoyment he would have had from a visit for which he had to travel less far. The alternative assumption, that $\frac{\mathrm{dl}}{\mathrm{dd}}>0$, means that the consumer "packs more into a visit" in response to the longer (and presumably more expensive) trip that had to be taken. The result is that a visit from farther away has more enjoyment attached to it than a closer (less expensive) visit.

To evaluate the bound and the consumer benefits of closer provision in a particular case, we turn next to calibration of an actual utility function and computation of bound (8) using casino data for the United States.

${ }^{7}$ That is, the enjoyment attached to a visit in which the consumer spent more because he had to travel a longer distance is greater than the enjoyment attached to one of many frequent visits where the distance traveled is small. 


\section{CONSUMER DISTANCE SURPLUS}

In section III we learned that information about visits, expenditure per visit, and distance allows us to infer information about the value of having casinos (or other service providers) distributed in more locations. Under the assumptions, plotting the number of visits versus expenditure per visit produces a demand-curve-like relation. The consumer-surplus-like area under this curve between the expenditure associated with the greater distance and the smaller expenditure associated with the lesser distance produces an upper bound for consumer benefits. In some cases the measure is exact. In other cases the bound could exceed true benefits by a large margin.

In this section we benchmark two utility functions to market data for casinos that relate distance, expenditure per visit, and frequency of visit. ${ }^{8}$ From the consumer optimization problem we compute the exact consumer distance surplus associated with having casinos at distance $d_{1}=0$ compared to the larger distance $\mathrm{d}_{0}$. The distance surplus computed can be interpreted as the consumer's answer to the question, "How much income each year would you be willing to give up in order to have access to casinos $d_{1}=0$ miles away compared to casinos $d_{0}=500$ miles away?" We also compare the exact distance surplus computed this way to the distance surplus that would be estimated from observing $d, g$, and V alone and using the bound.

\section{A. Additive Intensity}

The first computation uses a standard Constant Elasticity of Substitution (CES) utility function of the form

$$
u=u(x, V, I(g, d))=A_{0}\left[A_{1} x^{\frac{\sigma-1}{\sigma}}+A_{2} v^{\frac{\sigma-1}{\sigma}}\right]^{\frac{\sigma}{\sigma-1}}+I(g, d),
$$

where $\mathrm{x}$ is consumption of a composite good having price $\mathrm{p}=1$ and $\mathrm{V}$ is the number of visits to the casino. In equation (9), represents the elasticity of substitution and constants $A_{0}, A_{1}$, and $A_{2}$ are free parameters. The only feature not present in a standard CES utility function is the visit intensity term, $I(g, d)$, which (9) assumes enters in an additively separable way.

The components of (9) are chosen to match empirical data describing demand for casino services at two selected points. Table 1 reports the relationship between distance and demand in a sample that includes Las Vegas, Atlantic City, and Illinois casinos. ${ }^{9}$ Adults living between zero and 35 miles from casinos, for example, averaged expenditures of $\$ 125.70$ per year, or $\$ 157.30$ in 1998 dollars. We assume that the consumer has $\$ 40,000$ annual income. Constants $\mathrm{A}_{0}, \mathrm{~A}_{1}$, and $\mathrm{A}_{2}$ are chosen so that at the first benchmark, $d=0$, the consumer visits the casino 3.63

\footnotetext{
${ }^{8}$ An econometric estimation of utility function parameters would be another strategy if one has appropriate data. ${ }^{9}$ See Grinols and Omorov (1996).
} 
times per year and casino expenditures are $g=\$ 55$ per visit, or $\$ 200$ per year..$^{10} \mathrm{By}$ benchmarking the first point to $\$ 200$, therefore, we intentionally overstate the importance of casinos to the consumer's budget relative to this data.

TABLE 1

Distance and Demand Data: Casinos, 1990

\begin{tabular}{lccccc}
\hline & \multicolumn{5}{c}{ Distance of Gambler from Casino in Miles } \\
& $0-35$ & $35-75$ & $75-150$ & $150-300$ & Over 300 \\
\hline Expenditure/Visit & $\$ 35.31$ & $\$ 62.39$ & $\$ 64.54$ & $\$ 85.45$ & 143.01 \\
Visits/Adult & 3.56 & 1.56 & 0.73 & 0.48 & 0.10 \\
Expenditure/Yr & $\$ 125.70$ & $\$ 97.33$ & $\$ 47.11$ & $\$ 41.02$ & 14.30 \\
Expenditure/Yr 1997 $\$$ & $\$ 154.71$ & $\$ 119.79$ & $\$ 57.99$ & $\$ 50.48$ & 17.60 \\
Adult Population & 900,290 & $4,572,280$ & $18,734,095$ & $32,221,396$ & $119,540,700$ \\
\hline
\end{tabular}

$\mathrm{I}(\mathrm{g}$, $\mathrm{d})$ takes the form $\mathrm{c}_{2} \mathrm{~g}^{2}+\mathrm{c}_{1} \mathrm{~g}+\mathrm{c}_{0}$ for values of $\mathrm{g} \in\left(0, \mathrm{~g}_{1}\right)$, where $\mathrm{g}_{1}$ is a function of $\mathrm{d}$ and $\mathrm{I}(\mathrm{g}, \mathrm{d})$ is constant at its maximum value for $\mathrm{g}$ greater than $\mathrm{g}_{1} \cdot{ }^{11}$ This leads to interior solutions for the consumer's choice of $g$ where the optimized choice $g^{*} \in\left(0, g_{1}\right)$. Coefficients $c_{2}, c_{1}$, and $c_{0}$ are chosen so that I rises in $g$ and falls with d.

The second benchmark point is chosen to agree with Table 1 at $d=500$ miles. Parameters are set so that the consumer spends $\$ 176$ per visit, or, in the alternate case, so that the consumer visits 0.1 times per year. These two figures agree with the Over 300 column of Table 1.

The results are given in Table 2. As shown there, utility is 100 in the situation where $d=0$ and the consumer spends $\$ 200$ on casinos, making 3.63 visits per year. When the casino is located 500 miles away, visits drop to 0.0109 and expenditures rise to $\$ 176$ per visit (this expenditure per visit agrees exactly with the Table 1 expenditure per visit for adults living more than 300 miles from the casino). Utility falls from 100 to 99.947 . The right-hand column shows that this is equivalent to lowering consumer income by $\$ 49.44$ and leaving the casino at $\mathrm{d}=0 .{ }^{12}$ If we benchmark so that the consumer chooses to visit 0.1 times per year when the casino is 500 miles away (this visit frequency matches the Table 1 visit frequency for adults more than 300 miles from the casino), we find that utility is reduced by an amount equivalent to the effect of reducing income by $\$ 46.63$.

\section{TABLE 2}

Consumer Distance Surplus

Additively Separable Intensity Case

\begin{tabular}{lcccccc}
\hline & Variable & \multicolumn{5}{c}{ Results } \\
\hline Distance (Miles) & $\mathrm{d}$ & 0 & 500 & 500 & 0 & 0 \\
Expenditure per Visit & $\mathrm{g}$ & $\$ 55.00$ & $\$ 176.00$ & $\$ 112.96$ & $\$ 55.00$ & $\$ 55.00$ \\
Frequencey (Visits/Yr) & $\mathrm{V}$ & 3.6363 & 0.0109 & 0.1000 & 0.0999 & 3.6321 \\
Expenditure & $\mathrm{gV}$ & $\$ 200.00$ & $\$ 1.92$ & $\$ 11.30$ & $\$ 11.28$ & $\$ 199.77$ \\
Consumer Ann. Inc. & $\mathrm{Income}$ & $\$ 40,000$ & $\$ 40,000$ & $\$ 40,000$ & $\$ 40,000-\$ 49.44$ & $\$ 40,000-\$ 46.63$ \\
Utility & $\mathrm{U}(\mathrm{x}, \mathrm{V}, \mathrm{I}(\mathrm{g}, \mathrm{d}))$ & 100 & 99.947 & 99.995 & 99.947 & 99.995 \\
\hline
\end{tabular}

${ }^{10}$ Casino expenditures per year equal the amount lost at casinos, not the amount wagered. An average adult living within 35 miles of casinos can be expected to lose between $\$ 150$ and $\$ 200$ annually depending on which part of the country one samples.

${ }^{11}$ See appendix for numerical details.

${ }^{12}$ Using $\mathrm{d}=0$ agrees with the formula for consumer benefits in section II. 
We now consider the effect of distance in a CES function altered so that coefficient $A_{2}=I(g, d)=c_{2} g^{2}+c_{1} g+c_{0}$ for $g \epsilon\left(0, g_{1}\right)$ for appropriately chosen upper bound $g_{1}$.

\section{B. Multiplicative Intensity}

The second computation uses a CES function of the form

$$
\mathrm{U}=\mathrm{A}_{0}\left[\mathrm{~A}_{1} \mathrm{x}^{\frac{\sigma-1}{\sigma}}+\mathrm{I}(\mathrm{g}, \mathrm{d}) \mathrm{V}^{\frac{\sigma-1}{\sigma}}\right]^{\frac{\sigma}{\sigma-1}},
$$

where, as before, $\mathrm{x}$ is consumption of a composite good having price $\mathrm{p}=1$ and $\mathrm{V}$ is the number of visits to the casino. The consumer has $\$ 40,000$ annual income (as before), and constants $A_{0}, A_{1}$, and $I(g, d)$ are chosen so that at $d=0$ the consumer visits the casino 3.63 times per year, spending $g=\$ 55$ per visit, or $\$ 200$ per year on casino expenditures. When $d=500$, parameters are set so that the consumer chooses to spend $\$ 176$ per visit (first simulation), or to make 0.1 visits per year (second simulation), respectively. These two alternatives match the corresponding figures for Table 1 when the casino is more than 300 miles away.

The results of the second simulation are given in Table 3 . They are similar to the results of the additively separable case. As shown in Table 3, utility is 100 in the situation where $d=0$ and the consumer spends $\$ 200$ on casinos, making 3.63 visits per year. When the casino is located 500 miles away, visits drop to less than 0.01 , expenditures rise to $\$ 176$ per visit, and utility falls from 100 to 99.876 . As the right-hand column shows, this is equivalent to lowering consumer income by $\$ 49.66$ and leaving the casino at $d=0$. If we benchmark so that the consumer chooses to visit exactly 0.1 times per year when the casino is 500 miles away (this visit frequency matches exactly the Table 1 visit frequency for adults more than 300 miles from the casino), we find that utility is reduced by an amount equivalent to lowering income by $\$ 47.36$.

TABLE 3

Consumer Distance Surplus

\begin{tabular}{lcccccc}
\hline & Variable & \multicolumn{5}{c}{ Results } \\
\hline Distance (Miles) & $\mathrm{d}$ & 0 & 500 & 500 & 0 & 0 \\
Expenditure per Visit & $\mathrm{g}$ & $\$ 55.00$ & $\$ 176.00$ & $\$ 110.46$ & $\$ 55.00$ & $\$ 55.00$ \\
Frequencey (Visits/Yr) & $\mathrm{V}$ & 3.6363 & 0.0093 & 0.1000 & 3.63185 & 3.63206 \\
Expenditure & $\mathrm{gV}$ & $\$ 200.00$ & $\$ 1.64$ & $\$ 11.03$ & $\$ 199.75$ & $\$ 199.76$ \\
Consumer Ann. Inc. & $\mathrm{Income}$ & $\$ 40,000$ & $\$ 40,000$ & $\$ 40,000$ & $\$ 40,000-\$ 49.66$ & $\$ 40,000-\$ 47.36$ \\
Utility & $\mathrm{U}(\mathbf{x}, \mathrm{V}, \mathrm{I}(\mathrm{g}, \mathrm{d}))$ & 100 & 99.876 & 99.882 & 99.876 & 99.882 \\
\hline
\end{tabular}

The raw or unadjusted simulations therefore show that the consumer distance benefit of having casinos located nearby range between $\$ 46.63$ and $\$ 49.66$. The average of the four simulations is $\$ 48.27$.

Using the figures in Table 1 to plot number of visits on the horizontal axis and expenditure per visit on the vertical axis, we can calculate the area bounded by the resulting curve and the two expenditures per visit (\$143.01 and \$35.31) that correspond to distances 500 miles and zero miles. The integral approximated this 
way, $\int_{d_{0}}^{d_{1}} V d g=\$ 101.13$, acts as an upper bound, but overstates the exact figures generated by the utility function in Tables 2 and 3 .

\section{Estimates of the Value of Casino Expansion for Nonproblem Gamblers in the United States, 1990}

In this section we use the preceding information to report the value to the average household for nonproblem gambler households of casino expansion compared to the pre-1990 situation. Research indicates that approximately one-third to as much as one-half of casino revenues come from problem and pathological (P\&P) gamblers in the long run. ${ }^{13}$ To report the consumer benefits for nonproblem and nonpathological gamblers, the revenues of P\&P gamblers must be separated from the Table 1 totals. This changes the figures in Tables 2 and 3 proportionately. Reducing Table 2 and 3 benefits by 33 to 50 percent means benefits to non-P\&P gamblers are between $\$ 24$ and $\$ 33$.

Addiction is the state of being given up to a practice or habit to such an extent that cessation causes severe trauma. Normally, narcotics, cigarettes, etc., are the object of addiction. However, P\&P gambling increasingly is understood in terms of addiction characterized by the same type of behavior exhibited by those addicted to substances such as drugs or alcohol. Addiction presents a problem to the economic paradigm predicated on rational choice. How should we treat demand derived from addiction? If addiction is not rational (the individual experiences regret, pain, and worsened utility because of his choices), then this demand should be treated differently in some way from conventional demand. Resolving the question about how to measure consumer benefits by the addicted is beyond the scope of the present paper. Therefore, we take a less controversial route. Because we know that the combined figures reported in the previous section are tainted by including in them the substantial revenues of P\&P gamblers, we report here the separate consumer distance benefits computed for non-P\&P gamblers in addition to the totals reported in part B. We also deal with the more minor issue that not all consumers in 1990 lived 500 or more miles from a casino.

Before 1990, only Nevada and Atlantic City had casinos. The U.S. population lived different distances from Nevada and Atlantic City casinos. To compute distance benefits to the average non-P\&P gambler of expanding casinos from the pre-1990 situation to a counterfactual situation in which every adult has a casino next door, we subtract the demand due to P\&P gamblers and adjust for the geographic distribution of the population.

Using the utility model of Table 3 , we compute consumer distance surplus for the midpoint distances of Table 1 (i.e., 17.5 miles, 55 miles, 112.5 miles, 225 miles, and 500 miles). Averaging the distance surplus over the numbers of people at each distance reported in Table 1 indicates that direct consumer distance benefits are

\footnotetext{
${ }^{13}$ See Grinols and Omorov (1997) for a discussion. Lesieur (1996) considers a number of different locations and types of gambling, for example, finding that the share of revenues attributable to problem gamblers in casino gambling reached 48.7 and 55 percent in the two highest cases.
} 
not greater than $\$ 21-\$ 30$, with a midpoint of $\$ 26$. Most people lived 500 or more miles from a casino prior to 1990, so adjusting for those relatively few who lived closer produces an average benefit that differs from the benefit to those living 500 miles away by only about 10 percent.

In practice, discrete observations of distance, visit frequency, and expenditure per visit do not provide a complete picture of the relationship between the distance, visits, and expenditure per visit because the observation triplets must be sampled at a finite number of separated points. ${ }^{14}$ Depending on the number of points sampled (and thus the accuracy of the interpolations), one gets better or worse estimates. Interpolating between $(g, V)$ pairs for the five sample points available in Table 1 results in overestimates of the true consumer distance surplus as high as 10 percent. In most cases, however, the error is less than 5 percent.

\section{SUMMARY AND EVALUATIVE DISCUSSION}

The relationship between distance and demand is important to a number of public policy questions that relate to siting of entertainment complexes. For example, should a metropolitan area contribute tax dollars to a sports stadium at site $\mathrm{A}$, which is close to the population center but expensive, or contribute less to site B, farther away? Should a city encourage the licensing of a casino that will provide benefits from closer access but may have associated costly negative social externalities? The answer to these and related questions depends on the ratio of benefits to costs, where benefits include (1) consumer distance benefits; (2) change in net tax collections; and (3) change in net profits to business. Of the three components, the computation of consumer distance benefits is least well understood.

Working from utility optimization and taking into account the special features of gambling demand, this paper investigated the computation of consumer distance surplus in a class of consumer demand models, showed that a consumersurplus-like upper bound on distance benefits was possible, and benchmarked a CES utility function to data on distance and demand for casino visits. The simulations found that consumer distance benefits for the non-P\&P population associated with reducing distance from 500 to zero miles ranged from $\$ 24$ to $\$ 33$, with a midpoint of $\$ 28.50$. Taking account of the fact that some adults already lived closer to a casino than 500 miles in 1990, the analysis implies that the average consumer distance benefits of having a casino close to every adult, compared to the actual 1990 situation, is approximately $\$ 26$.

\footnotetext{
${ }^{14}$ This results anytime one approximates a curve with linear segments.
} 


\section{APPENDIX}

Table 2 computations are based on the following specifications:

$$
\mathrm{I}(\mathrm{g}, \mathrm{d})=\mathrm{A}_{0}\left(\mathrm{c}_{2} \mathrm{~g}^{2}+\mathrm{c}_{1} \mathrm{~g}+\mathrm{c}_{0}\right) \text {, }
$$

where:

$$
\begin{aligned}
& \mathrm{c}_{2}=\frac{\mathrm{A}_{20}-\mathrm{A}_{21}}{\left(\mathrm{~g}_{0}-\mathrm{g}_{1}\right)^{2}} \\
& \mathrm{c}_{1}=\frac{2\left(\mathrm{~A}_{21}-\mathrm{A}_{20}\right) \mathrm{g}_{1}}{\left(\mathrm{~g}_{0}-\mathrm{g}_{1}\right)^{2}} \\
& \mathrm{c}_{0}=\frac{\mathrm{A}_{21} \mathrm{~g}_{0}\left(\mathrm{~g}_{0}-2 \mathrm{~g}_{1}\right)+\mathrm{A}_{20} \mathrm{~g}^{2}}{\left(\mathrm{~g}_{0}-\mathrm{g}_{1}\right)^{2}} \\
& \mathrm{~A}_{20}=1 \quad \mathrm{~A}_{21}=910^{5} \\
& \mathrm{~A}_{0}=\frac{1}{9400.5} \quad \mathrm{~A}_{1}=1 \quad \mathrm{~A}_{2}=8.560898338 \quad \sigma=5 \\
& \mathrm{~g}_{0}=1 \quad \mathrm{~g}_{1}=\left(1-\frac{\mathrm{d}}{500}\right) 55.005899577944+\frac{\mathrm{d}}{500} 176.00018530312197
\end{aligned}
$$

In the alternate simulation, where distance from the casino equal to 500 implies 0.1 visits per year, the coefficient 176.000 is replaced by 112.95599639288718 in the formula for $\mathrm{g}_{1}$.

Table 3 computations are based on the following specifications:

$$
\mathrm{I}(\mathrm{g}, \mathrm{d})=\mathrm{c}_{2} \mathrm{~g}^{2}+\mathrm{c}_{1} \mathrm{~g}+\mathrm{c}_{0},
$$

where the formulas for $\mathrm{C}_{2}, \mathrm{c}_{1}$, and $\mathrm{c}_{0}$ are as above and

$$
\begin{array}{ll}
\mathrm{A}_{20}=1 & \mathrm{~A}_{21}=10000 \\
\mathrm{~A}_{0}=\frac{1}{138.902710^{4}} & \mathrm{~A}_{1}=679.339 \quad \sigma=5 \\
\mathrm{~g}_{0}=1 & \mathrm{~g}_{1}=\left(1-\frac{\mathrm{d}}{500}\right) 153.926742127+\frac{\mathrm{d}}{500} 516.57315808 .
\end{array}
$$

In the alternate simulation, where distance from the casino equal to 500 implies 0.1 visits per year, the coefficient 516.57315808 is replaced by 319.990 in the formula for $g_{1}$.

In each case, the formula for $\mathrm{I}(\mathrm{g}, \mathrm{d})$ applies in the range of $\mathrm{g}>0$, where $\mathrm{I}(\mathrm{g}, \mathrm{d})$ is rising and, for larger $\mathrm{g}, \mathrm{I}(\mathrm{g}, \mathrm{d})$ takes its maximum value. For a given $\mathrm{d}$, utility was maximized for interior choices of $g$ and V using Mathematica Version 3.0 by Wolfram Research. 


\section{REFERENCES}

Becker, G.S. "A Theory of the Allocation of Time." Economic Journal 75 (September 1965), 493-517. Accounting for Tastes. Cambridge: Harvard University Press, 1996.

Bockstael, N.E., and K.E. McConnell. "Public Goods as Characteristics of NonMarket Commodities." Economic Journal 103 (September 1993), 1244-1257.

Grinols, E.L. "Bluff or Winning Hand?: Riverboat Gambling and Regional Employment and Unemployment." Illinois Business Review 50 (Spring 1994), 8-11.

"Time for a National Policy." Testimony in National Impact of Casino Gambling Proliferation: Hearing before the U.S. House Committee on Small Business, 103rd Cong. Washington, D.C.: U.S. Government Printing Office, Serial 103-104 (1995), 8-11, 76.

. "Incentives Explain Gambling's Growth." Forum for Applied Research and Public Policy 11 (2) (Summer 1996), 119-124.

Grinols, E.L., and J.D. Omorov. "Development or Dreamfield Delusions: Assessing Casino Gambling's Costs and Benefits." The Journal of Law and Commerce 16 (1) (1996), 49-87.

"Who Loses When Casinos Win?" Illinois Business Review 53 (Spring 1997), 7-11, 19.

Larson, D.M. "Separability and the Shadow Value of Time." American Journal of Agricultural Economics 75 (August 1993), 572-577.

Lesieur, H. "Measuring the Costs of Pathological Gambling: Saying Too Much With Too Little." National Conference on Gambling Behavior of the National Council on Problem Gambling, Chicago, IL, 3-5 September 1996, Legislative Guide for Responsible Gaming in Your State. The Council on Compulsive Gambling of New Jersey, Inc., Trenton, NJ, 25 January, 1997.

McConnell, K.E., and I. Strand. "Measuring the Cost of Time in Recreation Demand Analysis: An Application to Sportfishing." American Journal of Agricultural Economics 63 (February 1981), 153-156.

Smith, V.K. "Time and Valuation of Environmental Resources." Manuscript, Duke University, October 1997. 